\title{
ENTOMOLOGY
}

\section{Boreoheptagyia ortladamellica sp. nov. (Diptera, Chironomidae) from Italian Alps}

\author{
B. Rossaro
}

Department of Food, Environmental, and Nutritional Sciences (DeFENS), University of Milan, Italy

\begin{abstract}
A new species from Italian Alps, Boreoheptagyia ortladamellica (Diptera, Chironomidae), is here described. The species is presently known only as adult male, it is similar to B. tibetica, because of the female-like antenna in adult male, but it can be separated by the following characters: much larger size, darker colour, medially pointed aedeagal lobe, knob-like and heavy sclerotized inferior volsella, gonostylus enlarged at basis with short spiniform setae at apex.
\end{abstract}

\footnotetext{
Correspondence: Bruno Rossaro, Dipartimento di Scienze per gli Alimenti, la Nutrizione e l'Ambiente, Università degli Studi di Milano, Via Celoria 2, 20133, Milan, Italy.

Tel.: +39.02.503.16734

E-mail: bruno.rossaro@unimi.it
}

Key words: Boreoheptagyia ortladamellica; Italian Alps, Diptera, Chironomidae.

Acknowledgements: the author thanks prof. Eugenji Makarchenko, Institute of Biology and Soil Sciences, Far Eastern Branch of the Russian Academy of Sciences, 690022 Vladivostok - 22, Russia for having examined the manuscript and useful advices.

Conflict of interest: the author declares no potential conflict of interest.

To meet the requirements by the International Code of Zoological Nomenclature (ICZN), this article was registered at ZooBank (23 June 2017) under the following ZooBank Life Science Identifiers (LSID): 509CAABC-065F-4314-ACD3-44884EBCB777; AFF65E34-77A8481E-AF4B-75D67D390745

Received for publication: 20 June 2017.

Accepted for publication: 23 June 2017

(C) Copyright B. Rossaro, 2017

Licensee PAGEPress, Italy

Journal of Entomological and Acarological Research 2017; 49:6860

doi:10.4081/jear:2017.6860

This article is distributed under the terms of the Creative Commons Attribution Noncommercial License (by-nc 4.0) which permits any noncommercial use, distribution, and reproduction in any medium, provided the original author(s) and source are credited.

\section{Introduction}

The genus Boreoheptagyia Brundin, 1966 is the single genus in the tribe Boreoheptagyiini, it includes at present 22 species (Ashe \& O'Connor, 2009), mostly from Palaearctic Region (Makarchenko et al., 2008). The larvae live in cold fast streams and tolerate high current velocity (Thienemann, 1954). The adults are able to fly but do not assemble in swarms (Serra-Tosio, 1989). Because of their restricted habitat and their low attitude to disperse they are a potentially interesting group from a biogeographical point of view, with many species known only from very restricted areas (Moubayed, 1993). A new species from Italian Alps was captured as adult male in three localities in the Central Alps and is here described.

\section{Materials and methods}

The adult specimens were collected with a sweep net near rivers, streams and lakes. The material was preserved in $70 \%$ ethanol. The specimens were cleared in $10 \% \mathrm{KOH}$ after the separation of wings and rinsed, including wings, in acetic acid, then transferred in xylene:phenol 3:1 (Wirth \& Marston, 1968), finally mounted in Canada Balsam on slides. Morphological terminology and abbreviations follow Sæther (1980). All measures are in $\mu \mathrm{m}$ unless otherwise stated. Holotype and paratypes are deposited in the Department of Food, Environmental and Nutritional Sciences, Università degli Studi di Milano, Italy.

\section{Boreoheptagyia ortladamellica Rossaro sp. nov.}

(Figures 1 and 2)

\section{Type material}

Holotype: adult male, Italy, Trentino Alto Adige, Adamello Glacier, glacial stream below Vedretta Lobbia, N 46¹1'51" - E 10³5'30.68”, 12.IX.1990, leg. Rossaro.

PARATYPES: three adult males, Italy, Lombardia, Ortles Glacier, glacial stream below Ercavallo lake, N 46¹9'43.18'" - E 10³2'37.24”, 16.VIII.1979, leg. Rossaro, adult male, Italy, Trentino-Alto Adige, near Niscli glacial stream, N 4606'7.93”' E 10³8’30.21”, 30.VII.1997, leg. Rossaro. 

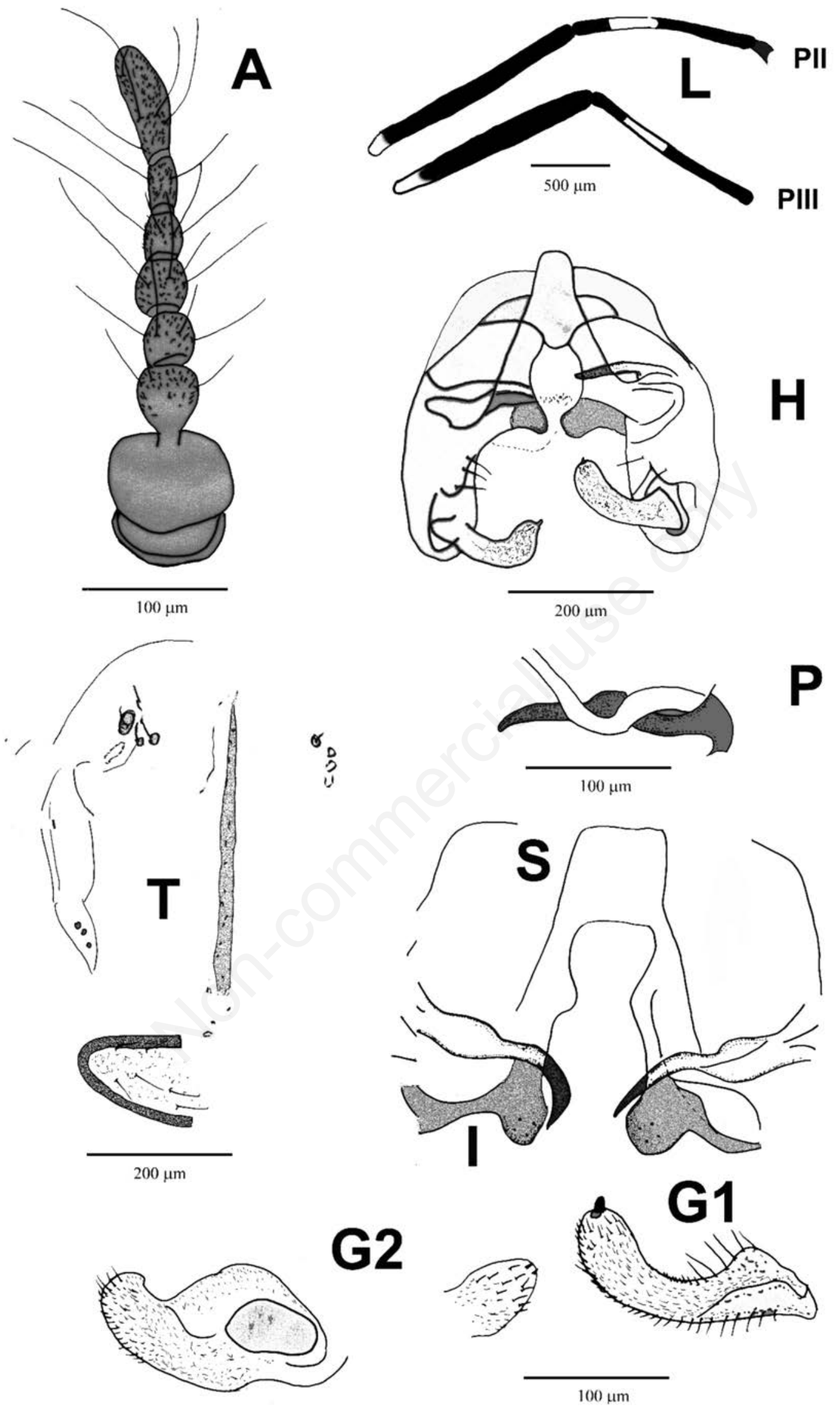

Figure 1. A) antenna, L) median and posterior femur and tibia, T) thorax, H) male hypopygium, P) aedeagal lobe, S) sternapodeme, I) inferior volsella, G1) G2) gonostylus. 


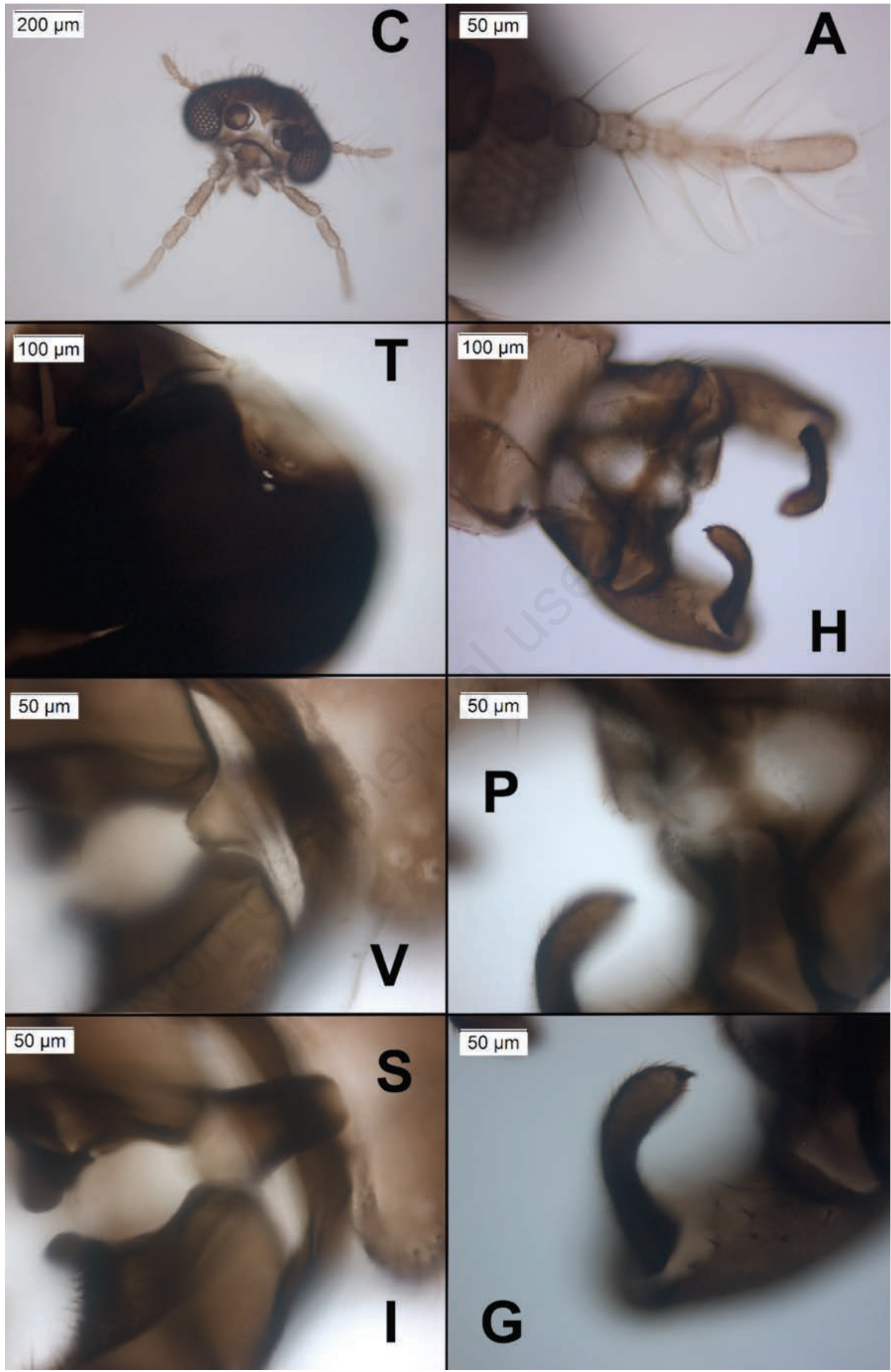

Figure 2. C) head, A) antenna, T) thorax, H) male hypopygium, V) pars ventralis, P) aedeagal lobe, S) sternapodeme, I) inferior volsella, $\mathrm{G})$ gonostylus. 
Table 1. Length in $\mu \mathrm{m}$ and proportions of leg segments.

\begin{tabular}{lcccccccccc} 
& Fe & Ti & Tal & Ta2 & Ta3 & Ta4 & Ta5 & LR & BV & SV \\
PI & 1387 & 1360 & 856 & 370 & 213 & 84 & 161 & 0.63 & 4.35 & 3.21 \\
PII & 1683 & 1377 & 797 & 344 & 167 & 75 & 192 & 0.58 & 4.96 & 3.84 \\
\hline PIII & 1666 & 1591 & 976 & 498 & 278 & 77 & 172 & 0.61 & 4.13 & 3.34 \\
\hline
\end{tabular}

\section{Derivatio nominis}

From the mountains were the species was captured, all belonging to the Ortles- Adamello group.

\section{Diagnosis}

Large species, antenna female-like with 6 flagellomeres, tibiae with white rings, hypopygium with a median pointed aedeagal lobe, knob-like, heavily sclerotized inferior volsella, gonostylus enlarged at basis.

\section{Description}

TotAl Length: $3.334 \mathrm{~mm}$; wing length $2.514 \mathrm{~mm}$,

COLORATION: thorax and abdomen dark brown, legs: coxae light, femura dark brown except a light proximal part, tibiae dark brown with white rings in the middle, tarsomeres uniformly brown, but lighter than femura.

HEAD (Figure 2C): Eyes bare without dorsomedial extension. About 10-15 vertical setae, not separable into inner and outer verticals, 12 orbitals, 1-3 frontals, 10-12 clypeals. Antenna (Figure 1A, 2A) female-like, with 6 flagellomeres, without plume, two sensilla chaetica on segments 4-6. Length of antennal segments: 56:35:37:33:37:80 $\mu \mathrm{m} \mathrm{AR}=0.40$. Palpomeres length: 40-45:66-72:118-128:100-111:150-184 $\mu \mathrm{m}$. Head wide/palpal length: about 0.9 .

THORAX: Antepronotum with 6 ventral antepronotals, 25-30 acrostichals almost in one row (Figure 1T, 2T), at most $10 \mu \mathrm{m}$ long, dorsocentrals reduced to 2-3 setae in anterior position, near to humeral area, in a large white spot, one-two white circular areas in the humeral region (Figure 1T, 2T), 16 prealars in two groups, an anterior group with 6 setae and a posterior group with 10 setae in a white area, preepisternals absent, scutellum with about 20 setae. Wings: Damaged, many veins not clearly distinguishable, $R$ vein with setae, wing membrane with coarse microtrichia 5-7 $\mu \mathrm{m}$ long. LEGS: Dark brown, femura and tibiae darker than tarsi, femura dark brown, with only a very short proximal white part extended for $1 / 10$, tibiae with a white ring extended about $1 / 5$ of the total length of tibia, in the proximal part (Table 1 and Figure 1L).

HYPOPYGIUM (Figure 1H, 2H). Tergite IX without anal point, pars ventralis well visible (Figure 2V), large, rounded, sternapodeme narrow and robust (Figure 1H, 2S), superior volsella rounded, very poorly projecting (Figure 1S), aedeagal lobe sclerotized, pointed on the median side (Figure 1I,P, 2P), inferior volsella knob-like, very sclerotized (Figure 1I, 2I), gonostylus widest in the basal 1/3 with one short megaseta and many short spiniform setae near the apex (Figure 1G1, G2, 2G).

\section{Remarks}

B. ortladamellica can be separated from all the other Boreoheptagyia species with female like antenna, by the knob-like sclerotized inferior volsella and the shape of gonostylus enlarged in the basal $1 / 3$ with spiniform setae at apex. The species is very similar to B. tibetica (Makarchenko et al., 1996, 2008), from which it differs because of much larger size, darker colour, medially pointed aedeagal lobe, knob-like and heavy sclerotized inferior volsella, gonostylus with short spiniform setae at apex.

\section{References}

ASHE P., O'CONNOR JP., 2009 - A World Catalogue of Chironomidae (Diptera). Part 1. Buchonomyiinae, Chilenomyiinae, Podonominae, Aphroteniinae, Tanypodinae, Usambaromyiinae, Diamesinae, Prodiamesinae and Telmatogetoninae. - Irish Biogeographical Society and National Museum of Ireland, Dublin.

MAKARCHENKO E.A., ENDO K., WU J., WANG X., 2008 - A review of Boreoheptagyia Brundin, 1966 (Chironomidae: Diamesinae) from East Asia and bordering territories, with the description of five new species. - Zootaxa 1817: 1-17.

MAKARCHENKO E.A., WANG X., WILLASSEN E., 1996 - A new species of Boreoheptagyia Brundin (Diptera, Chironomidae) from Tibet (China). - Jap. J. Ent. 64: 825-829.

MOUBAYED J., 1993 - Boreoheptagyia phoenicia sp. n.(Diptera, Chironomidae, Diamesinae) from a Lebanese mountain spring. In: Bund, W. J. van de and Kraak, M. H. S. (eds.): Proc. 11th Int. Symp. on Chironomidae, Amsterdam, 12-14 August 1991. - Netherl. J. aquat. Ecol. 26: 187-190. (“1992”)

SÆTHER O.A., 1980 - Glossary of chironomid morphology terminology (Diptera: Chironomidae). - Entomol. Scand. Suppl. 14: 51.

SERRA-TOSIO B., 1989 - Révision des espèces ouest-paléarctiques et néarctiques de Boreoheptagyia Brundin avec des clés pour les larves, les nymphes et les imagos (Diptera, Chironomidae). - Spixiana 11: 133-173.

THIENEMANN A., 1954 - Chironomus. Leben, Verbreitung und wirtschaftliche Bedeutung der Chironomiden. Binnengewässer20: 834 pp.

WIRTH WW., MARSTON N., 1968 - A method for mounting small insects on microscope slides in Canada Balsam. - Ann. Entomol. Soc. Am. 61: 783-784. 